\title{
A Case Study on Generation and Composition of Solid Waste in Ward no. 53 of Belagavi city
}

\author{
Amar S. Byakodi \\ Assistant Professor, Dept. of Civil Engineering, \\ Angadi Institute of Technology and Management, Belagavi, Karnataka, India \\ Suresh Babu B. T. \\ Professor, Dept. of Civil Engineering, \\ Angadi Institute of Technology and Management, Belagavi, Karnataka, India.
}

\begin{abstract}
Solid waste is the unwanted or useless solid material generated from combined residential, industrial and commercial activities in the given area. Belagavi city has a population of six lakhs as per 2011 census and also there are 58 wards in total. For the present study ward No. 53 is considered, since it is a developed residential area. Twelve house were selected considering standard of living of residents and solid waste was collected from these houses to procure a representative sample. Solid waste was collected in three different bins as (i) kitchen waste (ii) paper \& plastics (iii) other waste, from each house. The collected solid waste is immediately weighed and recorded. The study shows a total of 2.80 tonne of solid waste is generated per day in ward No. 53 and the same is collected by the municipal authorities by door to door collection system.
\end{abstract}

Keywords -- solid waste, generation, composition, Belagavi city

\section{INTRODUCTION}

Solid waste collection system is one among service provided by municipal authorities in the country to keep urban centre clean. Solid waste is the unwanted or useless solid materials generated from combined, residential, industrial and commercial activities in a given area. It may be categorised according to its origin (domestic, industrial, commercial, construction or institutional) according to hazard potential (toxic, non-toxic, flammable, waste radioactive, infectious etc.). Management of solid waste reduces or eliminates adverse impact on the environment and human health and supports economic development and improved quality of life [1].

As per the 2011 census population of Belagavi city is six lakhs and contain 58 wards in total. Total quantity of municipal solid waste generation 160 to 180 tonne per day. The Belagavi city corporation adopted two primary collection methods, viz. (i) door to door collection. (ii) provided metallic containers in a designed places in all over city limits. The collection of solid waste is carried out with the help of tippers, lorries with compactors. Belagavi Municipal corporation has 10 dumper vehicles, 280 steel containers, 2 lorries with compactors and 1 street sweeping machine. The present study is carried out to determine the status of solid waste collection system in ward No. 53 of Belagavi city.

\section{MATERIALS AND METHODOLOGY}

\section{A. Solid Waste Generation --}

Those activities in which are defined as so no longer being of value and are either thrown away or gathered for disposal. The generation of waste varies with classes of houses ( medium class, high class and low class) and industry to industry. The quantity and general composition of the waste material that is generated is of critical importance in the design and operation of solid waste management system. Unfortunately, reliable quantity and composition are difficult to obtain because most measurements are of the quantities collected although there are two methods of estimation subjected to limitations, the following are recommended [2].

- Load analysis: In this method, the quantity and composition of solid wastes are determined by recording the estimated volume and general composition of each load and waste delivered to landfill or transfer station during a specified period time. The total mass and mass distribution by composition is determined using average density for each waste category. 
- Mass volume analysis: This method of analysis is similar to the above method with the added feature that the mass of each load is also recorded. Unless the density of each waste category is determined separately, the mass distribution by composition must be derived using average density.

\section{B. Factors affect generation rates: \\ - Geographic location \\ - Season of the year \\ - Collection frequency \\ - Use of lechate waste grinders \\ - Characteristics of produce \\ - Extent salvaging and recycling \\ - Public attitudes \\ - Legislation}

\section{On Site Handling, Storage and Processing}

On site handling refers to the activities associated with handling of solid wastes until they are placed in the containers used for their storage before collection. Depending on the type of collection service, handling may also be required to move loaded container to the collection point and to return empty containers to the point where they are stored between collections.

In low and medium rise residential dwelling are placed in larger containers to await removal by the waste collection agency where curb collection is used, the resident is also responsible for planning the curb and for returning the empty containers to their storage location next to in the dwelling.

In high rise apartment wastes are picked up by building maintenance personnel or porters from each floor and taken to the basement service area. Taller to basement service area by the tenants or bugged and placed by the tenants in especially designed chutes with opening located at each floor.

Commercial and industrial solid wastes: In most office commercial and industrial buildings solid wastes that accumulate in the office or work locations usually are collected in relatively large containers mounted on rollers they are emptied into (i) Large storage container (ii) Compaction used in conjunction with the storage containers (iii) Stationary compactor that can compress the material into specially designed container (iv) Other processing equipment such as incineration.

The factors should consider for on-site storage: The type of container to be useful ,The container location, public health and aesthetics and The collection methods to be used containers : To a large extent, the type and capacities of the container used depend on the characteristics of the solid waste to be collected, the collection frequency, and the space available for the placement of container.

Container location : In newer residential areas, containers for solid waste usually are placed by the side or rear of the house. In order residential areas containers are located in alley. In low - rise multifamily apartment large containers are often placed in specially designed and designated enclosures. In high rise apartment storage containers are located in a basement or ground floor service area.

The location of container at existing commercial and industrial facilities depends on both the location of available space and accesses condition. In newer facilities, specific service areas have been included for this purpose. On site processing methods are use to recover usable materials from solid waste to reduce the volume or to alter the physical form. The most common on site processing operations include manual sorting, compactions ad incineration.

\section{Collection of solid waste --}

This involves four functional elements

- The types of collection services.

- The types of collection systems.

- An analysis of collection system.

- The general methodology involved in setting up collection routes.

\section{Collection services --}


Dunicipal collection service: Although a variety of collection services are used throughout the United States the 3 most common are curb, alley and backyard collection. Curb collection has gained popularity because labour costs for collection can be minimized.

> Commercial and Industrial collection services: The collection service provided to large apartment building, residential complexes and commercial and industrial activities typically is centred around the use of large movable and stationary containers and large stationary compactors. Compactors are of the type that can be used to compress material directly in to large container or to form bales that are then placed in large container that are then placed in large containers.

\section{Types of collection systems}

> Manual container system (MCS): collection system in which the containers used for the storage of wastes are hauled to the processing transfer, or disposed site, emptied, and returned to either their original location or some other location are defined as hauled container system. There are 2 main types of hauledcontainer systems

(i) Tilt frame container

(ii) Trash-trailer.

$>$ Stationary - container system : Collection systems in which the container used for the storage of wastes remain at the point of waste generation except when moved for the collection are defined as stationarycontainer system. Labour requirements for mechanically loaded stationary-container system are essentially the same as for hauled container systems. There are 2 main types of stationary systems(i) Those in which self-loading compactors are used. (ii) Those in which manually loaded vehicles are used [2].

\section{RESULTS AND DISCUSSION}

\section{A. Present status of the solid waste collection system in ward no 53 --}

The present study focuses on generation of municipal solid waste in ward No. 17 of Belagavi city. The city corporation consists of 58 wards, where the total quantity of municipal solid waste generation 160 to 180 tonne per day. The Belagavi city corporation adopted two primary collection methods. Those are (i) door to door collection (ii) provided metallic containers in a designed places in all over city limits. The collection of solid waste is carried out with the help of tippers, lorries with compactors. Belagavi Municipal corporation has 10 dumper vehicles, 280 steel containers, 2 lorries with compactors and 1 street sweeping machine. The present study is carried out to determine the status of solid waste collection system in ward No. 53 of Belagavi city.

The Belagavi city corporation manage the solid waste in 15 wards and remaining 43 wards are out sourced or contract based. The selected ward No. 53 (Mahantesh nagar) has an outsourced or contract based collection service.

The dust bins are mounted on moving vehicles where peoples dump their house waste in to those dust bins when the vehicle come to their respective houses. With a vehicle two persons will come one is driver and another person is helper. Who will collect the waste and dump in to vehicle container.

The collection frequency of the waste in ward No. 53 is 2.5 to 4 tonnes as per the municipal corporation analysis and the method of collection is door to door collection.

B.

al generation of solid waste from selected area --

Tot

During the study period solid waste samples were collected from 12 selected houses. The selection of houses were based on the living standard and habits of the residents. For the collection and segregation of solid waste, each house was provided with three boxes and plastic bags. The residents were instructed to dispose the solid waste based on its category as (i) Kitchen waste (ii) Paper \& Plastic (iii) Other waste. Every day the waste was collected from plastic carry bags and replaced with new ones. The collection of solid waste was carried out at 7:00 pm everyday and the waste collected was weighed immediately. 
Followings are the details of houses selected for the present study:

Table - 1 Details of houses sleeted for the study

\begin{tabular}{|c|l|}
\hline S.l No. & \multicolumn{1}{|c|}{ Owner of the house } \\
\hline 1 & Shashidhar Chiniwar \\
\hline 2 & Vijay Hedduurshetti \\
\hline 3 & Shashidhar kumar Hogarti \\
\hline 4 & Jayshankar Sunkadmath \\
\hline 5 & Mahantesh Sobarad \\
\hline 6 & Appasaheb Vibhuti \\
\hline 7 & Mustak Khan \\
\hline 8 & Narendra Bhamki \\
\hline 9 & Vivek Kokatnar \\
\hline 10 & Virappa Bidari \\
\hline 11 & Dayanand Sanadi \\
\hline 12 & Hema Kotagi \\
\hline
\end{tabular}

This map illustrates the location of houses selected for the collection of solid waste :

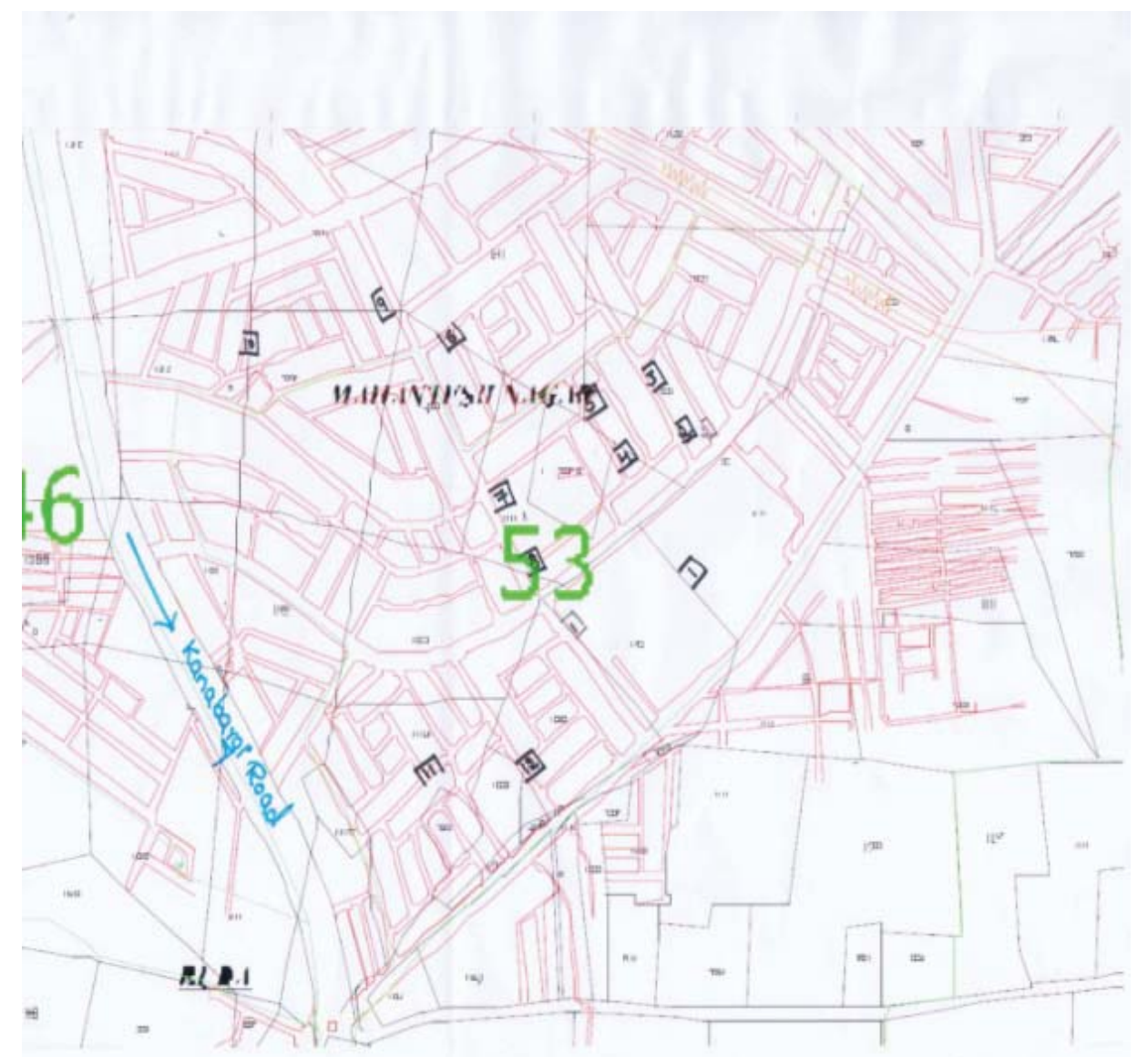

Figure 1. Location of houses selected for the present study 
The solid waste is collected from the selected houses every day and the data collected are tabulated below:

Table - 2 Details of solid waste collection from selected houses.

\begin{tabular}{|l|c|c|c|}
\hline \multicolumn{1}{|c|}{ Date:-19/03/2016 to 20/03/2016 } & Others (Kg) \\
\hline Houses & Kitchen waste (Kg) & Paper \& Plastic (Kg) & 0.100 \\
\hline 2. Chiniwar & 1.286 & 0.135 & 0.128 \\
\hline 3. Hogarti & 1.716 & 0.545 & 0.041 \\
\hline 4. Sunkandmath & 1.018 & 0.223 & 0.129 \\
\hline 5. Sobrad & 0.935 & 0.246 & 0.099 \\
\hline 6.Vibhuti & 0.835 & 0.615 & 0.826 \\
\hline 7.Khan & 0.810 & 0.215 & 0.084 \\
\hline 8.Jhamki & 0.638 & 0.146 & 0.020 \\
\hline 9.Kokatnaar & 1.216 & 0.109 & 0.214 \\
\hline 10.Bidari & 1.516 & 0.024 & 0.226 \\
\hline 11.Sanadi AVERAGE & 0.365 & 0.089 & 0.104 \\
\hline 12.Kotagi & 0.586 & 0.124 & 0.120 \\
\hline \multicolumn{2}{|c|}{1.826} & 0.286 & 0.174 \\
\hline
\end{tabular}

Table - 3 Details of solid waste collection from selected houses.

\begin{tabular}{|l|c|c|c|}
\hline \multicolumn{1}{|c|}{ Date:-21/03/2016 to 22/03/2016 } \\
\hline Houses & Kitchen waste $\mathbf{( K g )}$ & Paper \& Plastic $\mathbf{K g})$ & Others $\mathbf{~ K g})$ \\
\hline 1. Chiniwar & 1.196 & 0.315 & 0.025 \\
\hline 2. Heddurshetti & 1.806 & 1.205 & 0.059 \\
\hline 3. Hogarti & 0.992 & 0.485 & 0.085 \\
\hline 4. Sunkandmath & 1.012 & 0.315 & 0.015 \\
\hline 5. Sobrad & 0.786 & 0.029 & 0.315 \\
\hline 6.Vibhuti & 0.913 & 0.015 & 0.005 \\
\hline 7.Khan & 0.738 & 1.002 & 0.125 \\
\hline 8.Jhamki & 1.024 & 0.025 & 0.585 \\
\hline 9.Kokatnaar & 1.489 & 0.092 & 0.005 \\
\hline 10.Bidari & 0.286 & 0.055 & 0.215 \\
\hline 11.Sanadi AVERAGE & 0.613 & 0.515 & 0.445 \\
\hline 12.Kotagi & 1.712 & 0.615 & 0.023 \\
\hline
\end{tabular}


Table - 4 Details of solid waste collection from selected houses.

\begin{tabular}{|l|c|c|c|}
\hline \multicolumn{5}{|l|}{ Date:-23/03/2016 to 24/03/2016 } \\
\hline \multicolumn{1}{|c|}{ Houses } & Kitchen waste $\mathbf{( K g )}$ & Paper \& Plastic $\mathbf{( K g )}$ & Others $\mathbf{~ K g ) ~}$ \\
\hline 1. Chiniwar & 1.362 & 0.223 & 0.045 \\
\hline 2. Heddurshetti & 1.523 & 0.285 & 0.084 \\
\hline 3. Hogarti & 1.232 & 0.245 & 0.041 \\
\hline 4. Sunkandmath & 0.798 & 0.825 & 0.214 \\
\hline 5. Sobrad & 0.965 & 0.525 & 0.226 \\
\hline 6.Vibhuti & 0.756 & 0.363 & 0.104 \\
\hline 7.Khan & 1.012 & 0.125 & 0.121 \\
\hline 8.Jhamki & 0.923 & 0.115 & 0.092 \\
\hline 9.Kokatnaar & 1.462 & 0.101 & 0.126 \\
\hline 10.Bidari & 0.249 & 0.192 & 0.099 \\
\hline 11.Sanadi & 0.701 & 0.286 & 0.012 \\
\hline 12.Kotagi & 1.719 & 0.212 & 0.028 \\
\hline
\end{tabular}

Table - 5 Details of solid waste collection from selected houses.

\begin{tabular}{|l|c|c|c|}
\hline \multicolumn{1}{|c|}{ Date:-25/03/2016 to 26/03/2016 } \\
\hline \multicolumn{1}{|c|}{ Houses } & Kitchen waste (Kg) & Paper \& Plastic (Kg) & Others (Kg) \\
\hline 1. Chiniwar & 1.402 & 0.546 & 0.011 \\
\hline 2. Heddurshetti & 1.593 & 0.138 & 0.026 \\
\hline 3. Hogarti & 1.132 & 0.220 & 0.099 \\
\hline 4. Sunkandmath & 0.984 & 0.232 & 0.021 \\
\hline 5. Sobrad & 0.796 & 0.605 & 0.015 \\
\hline 6.Vibhuti & 0.798 & 0.216 & 0.022 \\
\hline 7.Khan & 0.762 & 0.142 & 0.085 \\
\hline 8.Jhamki & 1.141 & 0.102 & 0.026 \\
\hline 9.Kokatnaar & 1.623 & 0.020 & 0.191 \\
\hline 10.Bidari & 0.406 & 0.080 & 0.084 \\
\hline 11.Sanadi & 0.613 & 0.192 & 0125 \\
\hline 12.Kotagi & 1.961 & 0.280 & 0.115 \\
\hline
\end{tabular}


Table - 6 Details of solid waste collection from selected houses

\begin{tabular}{|l|c|c|c|}
\hline \multicolumn{1}{|l|}{ Date:- 27/03/2016 to 28/03/2016 } \\
\hline \multicolumn{1}{|c|}{ Houses } & Kitchen waste $\mathbf{( K g )}$ & Paper \& Plastic (Kg) & Others (Kg) \\
\hline 1. Chiniwar & 1.231 & 0.221 & 0.004 \\
\hline 2. Heddurshetti & 1.862 & 0.341 & 0.020 \\
\hline 3. Hogarti & 1.032 & 0.220 & 0.082 \\
\hline 4. Sunkandmath & 0.896 & 0.212 & 0.022 \\
\hline 5. Sobrad & 0.916 & 0.021 & 0.016 \\
\hline 6.Vibhuti & 0.813 & 0.014 & 0.064 \\
\hline 7.Khan & 0.796 & 0.121 & 0.076 \\
\hline 8.Jhamki & 1.401 & 0.212 & 0.126 \\
\hline 9.Kokatnaar & 1.354 & 0.142 & 0.117 \\
\hline 10.Bidari & 0.296 & 0.100 & 0.082 \\
\hline 11.Sanadi & 0.498 & 0.015 & 0.122 \\
\hline 12.Kotagi & 1.756 & 0.099 & 0.006 \\
\hline
\end{tabular}

Table - 7 Details of solid waste collection from selected houses.

\begin{tabular}{|l|c|c|c|}
\hline Date:-29/03/2016 to 30/03/2016 & \multicolumn{5}{l|}{ Others (Kg) } \\
\hline \multicolumn{1}{|c|}{ Houses } & Kitchen waste (Kg) & Paper \& Plastic (Kg) & 0.006 \\
\hline 1. Chiniwar & 1.562 & 0.642 & 0.028 \\
\hline 2. Heddurshetti & 1.231 & 0.216 & 0.121 \\
\hline 3. Hogarti & 1.357 & 0.454 & 0.087 \\
\hline 4. Sunkandmath & 1.234 & 0.094 & 0.128 \\
\hline 5. Sobrad & 0.976 & 0.121 & 0.135 \\
\hline 6.Vibhuti & 0.749 & 0.082 & 0.286 \\
\hline 7.Khan & 0.732 & 0.062 & 0.545 \\
\hline 8.Jhamki & 1.053 & 0.142 & 0.218 \\
\hline 9.Kokatnaar & 1.457 & 0.022 & 0.126 \\
\hline 10.Bidari & 0.198 & 0.028 & 0.099 \\
\hline 11.Sanadi & 0.497 & 0.121 & 0.100 \\
\hline 12.Kotagi & 1.712 & 0.011 & 0.179 \\
\hline
\end{tabular}


Table - 8 Details of solid waste collection from selected houses.

\begin{tabular}{|l|c|c|c|}
\hline Date:-31/03/2016 to 01/04/2016 \\
\hline \multicolumn{1}{|c|}{ Houses } & Kitchen waste (Kg) & Paper \& Plastic (Kg) & Others (Kg) \\
\hline 1. Chiniwar & 0.987 & 0.196 & 0.099 \\
\hline 2. Heddurshetti & 1.576 & 0.226 & 0.128 \\
\hline 3. Hogarti & 1.213 & 0.245 & 0.112 \\
\hline 4. Sunkandmath & 0.893 & 0.286 & 0.092 \\
\hline 5. Sobrad & 0.789 & 0.148 & 0.216 \\
\hline 6.Vibhuti & 0.876 & 0.088 & 0.222 \\
\hline 7.Khan & 1.679 & 0.060 & 0.236 \\
\hline 8.Jhamki & 1.356 & 0.128 & 0.345 \\
\hline 9.Kokatnaar & 0.389 & 0.029 & 0.096 \\
\hline 10.Bidari & 0.761 & 0.129 & 0.011 \\
\hline 11.Sanadi & 0.698 & 0.023 & 0.121 \\
\hline 12.Kotagi & 1.743 & 0.062 & 0.009 \\
\hline
\end{tabular}

Table - 8 Details of solid waste collection from selected houses.

\begin{tabular}{|l|c|c|c|}
\hline \multicolumn{1}{|c|}{ Date:-02/04/2016 to 3/04/2016 } & \multicolumn{3}{l|}{} \\
\hline Houses & Kitchen waste $\mathbf{( K g )}$ & Paper \& Plastic (Kg) & Others (Kg) \\
\hline 1. Chiniwar & 1.346 & 1.212 & 0.122 \\
\hline 2. Heddurshetti & 1.664 & 0.296 & 0.009 \\
\hline 3. Hogarti & 1.038 & 0.346 & 0.212 \\
\hline 4. Sunkandmath & 0.879 & 0.454 & 0.128 \\
\hline 5. Sobrad & 0.798 & 0.562 & 0.326 \\
\hline 6.Vibhuti & 0.731 & 0.029 & 0.099 \\
\hline 7.Khan & 0.861 & 0.011 & 0.028 \\
\hline 8.Jhamki & 1.346 & 0.121 & 0.212 \\
\hline 9.Kokatnaar & 1.537 & 0.215 & 0.010 \\
\hline 10.Bidari & 0.298 & 0.050 & 0.121 \\
\hline 11.Sanadi & 0.386 & 0.246 & 0.119 \\
\hline 12.Kotagi & 1.416 & 0.022 & 0.032 \\
\hline
\end{tabular}

C. Calculation-- 
Total No of houses

Total No of family

Total population
1200

1732

7211

Average occupancy of each houses is 4 numbers.

The total waste generation for each person as per our collection.

Kitchen waste $=\frac{1.062}{4}=0.2655 \mathrm{~kg}$

Plastic \& paper $=\frac{0.20101}{4}=0.0503 \mathrm{~kg}$

Other waste $=\frac{0.288}{4}=0.072 \mathrm{~kg}$

Total waste per person $=$ Kitchen waste + Plastic $\&$ Papers + Other waste

Total waste per person $=0.2655+0.0503+0.072$

Total waste per person $=0.3877 \mathrm{~kg}$

Total waste generation in ward no $53=$ Population $\mathrm{x}$ Waste generation per person

Total waste generation in ward no $53=7211 \times 0.3877$

Total waste generation in ward no $53=2795.70 \mathrm{~kg}$

Total generation in ton's $=\frac{2795.70}{1000}=2.8$ tonne.

\section{CONCLUSION}

Ward No. 53 is a area comprising of residential area and commercial area. The population of the selected study area is 7211. twelve houses were selected for the present study and selection of houses was based on the living standard and habits of the residents. The study shows that an average value of $0.3877 \mathrm{~kg}$ per person per day is generated from ward No. 53. Composition of solid waste include kitchen, plastic and paper, others. door collection (ii) provided metallic containers in a designed places in all over city limits. The collection of solid waste is carried out with the help of tippers, lorries with compactors. Belagavi Municipal corporation has 10 dumper vehicles, 280 steel containers, 2 lorries with compactors and 1 street sweeping machine. Total generation from the ward No. 53 is 2.8 tonne per day and the same is collected through door to door collection system.

\section{REFERENCES}

[1] S.M. Al-Salem, P. Lettieri, J. Baeyens, " Recycling and recovery routes of plastic solid waste (PSW): A review", Waste Management, 29, 2625-2643, 2009.

[2] George Tchobanoglous, Hilary Theisen, S. A. Vigil, "Integrated solid waste management: engineering principles and management issues", McGraw-Hill, 1993 edition.

[3] Lilliana Abarca Guerrero, Ger Maas, William Hogland, " Solid waste management challenges for cities in developing countries", Waste Management, 33, 220-232, 2013.

[4] Jockey B. Nyakaana, " Solid Waste Management In Urban Centers: The Case Of Kampala City - Uganda", East African Geographical Review, 19:1.

[5] David O. Olukanni, Oladipupo O. Akinyinka, Anthony N. Ede, Isaac. I. Akinwumi and Kolawole O. Ajanaku, " Appraisal of Municipal Solid Waste Management, Its Effect and Resource Potential in A Semi-Urban City: a Case Study", Journal of South African Business Research, IBIMA Publishing, Vol. 2014 (2014), Article ID 70569. 